\title{
Codesigning care improvements for women living with HIV: a patient-oriented deliberative dialogue workshop in Montréal, Quebec
}

\author{
Nadia O’Brien MPH PhD, Susan Law PhD, Karène Proulx-Boucher MA, Brigitte Ménard, \\ Lashanda Skerritt BSc, Isabelle Boucoiran MD MSc, Joseph Cox MD MSc, Neil Andersson MD PhD, \\ Alexandra de Pokomandy MD MSc
}

\section{Abstract}

Background: Care services have not been sufficiently adapted to meet the comprehensive care needs of women living with HIV. Our study objective was to engage patients and providers in codesigning care recommendations to improve care for this population in the province of Quebec.

Methods: We conducted a 5-hour deliberative dialogue workshop in April 2019 in Montréal as the final phase of a mixed-methods study investigating comprehensive care for women living with HIV. The study drew on data from the Canadian HIV Women's Sexual and Reproductive Health Cohort Study (CHIWOS). Recruitment was guided by a purposive maximum-variation sampling strategy to ensure an appropriate mix of participants and was facilitated by our existing CHIWOS networks. Participants included patients (women living with HIV) and HIV care providers (doctors, nurses, pharmacists). The workshop was facilitated professionally and included a synthesis of the evidence, small- and large-group deliberations, and voting on care improvements.

Results: Eight patients and 8 HIV care providers participated. Drawing on identified care priorities, the participants identified 4 relatively rapid care improvements and 3 longer-term improvements. The rapid care improvements included delegating medical acts to members of multidisciplinary care teams; greater involvement of HIV community members within care settings and health care decision-making; creating a women's health information booklet; and increasing HIV education among all health care providers and raising awareness of women's care needs beyond HIV-specific care among HIV care providers. The longer-term care improvements included advocating for complete financial coverage of antiretroviral therapy within the government-sponsored Medicare program, facilitating access to allied care providers (e.g., physiotherapists and psychologists) and launching a population-wide campaign to increase awareness about the Undetectable $=$ Untransmittable $(\mathrm{U}=\mathrm{U})$ initiative and other HIV advances.

Interpretation: The deliberative dialogue workshop yielded evidence-based, stakeholder-driven recommendations to improve the comprehensive care of women living with HIV in Quebec.

Plain language summary: Owing to the availability of effective treatments, people living with HIV now have a life expectancy approaching that of the general population. For those with access to treatment, HIV is now considered a manageable chronic disease. Despite these medical advances, women living with HIV in Canada experience challenges in accessing care and report important gaps in their HIV, reproductive and primary care needs. To improve care for this population, we brought together patients (women living with HIV) and care providers (doctors, nurses and pharmacists) in a workshop to cocreate appropriate and feasible care recommendations. This research was conducted as a closing phase of a substudy within a large Canadian study involving women living with HIV from 2011 to 2019. The workshop was conducted over 1 afternoon in Montréal and was led by a professional moderator. In the workshop, 8 patients and 8 care providers reviewed research findings and, based on their experience, discussed their top priorities for care improvements and identified changes that could be applied to improve care in the immediate and longer term. The participants identified numerous care improvements, including alleviating HIV-related stigma through public awareness campaigns, having certain care (e.g., Pap tests, contraceptive counselling) delivered by nurses, creating a women's health information booklet, and addressing the cost of HIV medications. Involving patients and providers in discussing research results and cocreating care recommendations is a valuable endeavour for engaging those with lived experience in the later stages of the research process, and may facilitate the transfer of research into action.

\section{Competing interests: None declared.}

This article has been peer reviewed.

Correspondence to: Alexandra de Pokomandy, alexandra.depokomandy @mcgill.ca

CMAJ Open 2020. DOI:10.9778/cmajo.20190158 
F

or the past 4 decades, health care systems and practices have evolved in response to the shifting realities of the HIV epidemic. ${ }^{1-3}$ In the 1980s, HIV care was focused largely on treating opportunistic infections and palliative care. In the mid-1990s, care transitioned to HIV specialists as complex antiretroviral therapy (ART) was introduced. ${ }^{1}$ Today, HIV is considered a manageable chronic disease. ${ }^{4}$ Treatment involves as few as 1 pill a day and care appointments every 3-6 months, and life expectancy nears that of the general Canadian population..$^{5}$ Affected populations have also changed over time. In the early days of the epidemic, HIV cases were primarily among men having sex with men, but HIV infection rates among women doubled between 1999 and 2012,6,7 and women made up $23.3 \%$ of the HIVpositive population in Canada in 2018. ${ }^{8}$

Yet, research evidence indicates that care delivery has not adapted sufficiently to meet women's comprehensive HIV care needs. A Canadian cohort study of women living with HIV showed that $56.4 \%$ of women experienced at least 1 gap in comprehensive care (i.e., viral suppression, Papanicolaou test, reproductive discussion or mammography). ${ }^{9}$ Furthermore, reproductive discussions with providers remain scarce, ${ }^{10,11}$ despite the importance of adopting strategies to prevent HIV transmission to sexual partners or infants, ${ }^{12}$ the potential toxicity of ART on the fetus ${ }^{13}$ and high rates of unplanned pregnancies. ${ }^{14}$ Women also experience challenges engaging consistently in HIV care, ${ }^{15-17}$ from HIV testing ${ }^{18}$ to ART adherence ${ }^{19}$ and sustained viral suppression..$^{20}$ Finally, women characterize their experience of HIV and women's health care as fragmented, influenced by care providers' lack of HIV knowledge and persistent HIV-related stigma. ${ }^{21}$

To ensure that future health care modifications respond adequately to these care gaps, patients and providers should be engaged in examining existing evidence and producing care recommendations to be implemented by policy-makers, AIDS service organizations, or fellow patients and providers. The potential contributions of patient and public engagement in health research and health care decision-making - such as in shaping patient- and family-centred approaches to chronic care, in tailoring services for marginalized populations and in identifying implementable solutions that are sustained over time ${ }^{22-25}$ - are well recognized. A 2018 article identified public engagement as crucial to enabling the Canadian health care system to reach its ideal of delivering effective and equitable care. ${ }^{26}$ Our study objective was to engage patients and providers in codesigning care recommendations to improve comprehensive care for women living with HIV in Quebec.

\section{Methods}

\section{Setting and design}

We conducted a deliberative dialogue workshop as the final phase of a mixed-methods study investigating comprehensive care for women living with HIV. The workshop was conducted over 1 afternoon (5 h) in April 2019 in a nonprofit conference facility in Montréal. The project drew on data from the Canadian HIV Women's Sexual and Reproductive
Health Cohort Study (CHIWOS) (www.CHIWOS.ca), ${ }^{27}$ a study anchored in participatory research approaches. ${ }^{28,29} \mathrm{We}$ chose to conduct a deliberative dialogue workshop as it is distinguished from other methods, such as focus groups, by these key principles: the use of evidence for critical examination, a mix of diverse participants, the valuing of experiential knowledge and skilled facilitation of discussions aimed at producing statements of the group's considered views. ${ }^{30-35}$ This method was compatible with our aim to move evidence to action by engaging those most apt to identify appropriate and feasible care recommendations: patients and providers.

Deliberative dialogue also aims to foster thoughtful exchanges, where convergent and divergent views are welcomed, rather than aiming for a consensus. ${ }^{36}$ Deliberations differ from focus groups in that the "research is used not so much to give participants a 'voice' ... but to create a process in which the participants themselves produce conclusions that can then be relayed to others, for example, policy makers." ${ }^{30}$ Deliberative dialogue, through the consideration of evidence and the exchange of ideas, values and priorities, contributes to the notion of a shared cognitive space or mutual understanding of an issue, and may thus facilitate the translation of evidence into action..$^{33} \mathrm{~A}$ deliberative approach is also consistent with participatory research and may be leveraged to further engage those affected by the research in the knowledge-translation and decision-making phases of the research. ${ }^{34,37-39}$

\section{Participant recruitment}

Recruitment was guided by a purposive maximum-variation sampling strategy to ensure an appropriate mix of participants. ${ }^{33,40} \mathrm{We}$ aimed to recruit women of different ages and ethnicities living with HIV to represent the communities affected by HIV in Canada, as well as women with various levels of participatory experience in research or AIDS service organizations to facilitate active participation. We also recruited different types of care providers (i.e., doctors, nurses, pharmacists). Patient recruitment was facilitated by our existing CHIWOS networks, including a list of CHIWOS participants who had indicated their interest in participating in future research. Following feedback from women living with HIV, we recruited providers first and communicated their names to patients so they could better assess whether they felt comfortable participating. All participants were offered a $\$ 100$ honorarium.

\section{Data collection}

One week before the workshop, we sent participants a lay summary of the evidence to be reviewed (Appendix 1, available at www.cmajopen.ca/content/8/2/E264/suppl/DC1). ${ }^{33,41}$ The evidence pertaining to women's comprehensive care gaps was drawn from the CHIWOS study and a systematic review conducted by the lead author (N.O.) (Box 1). An overview of the evidence was also presented at the beginning of the workshop, with time allotted for clarifying questions. The Quebec CHIWOS principal investigator was in attendance to answer questions and provide clarifications. 
Box 1: Sources and types of evidence provided to deliberative workshop participants

\begin{tabular}{|llll|}
\hline Source of evidence & Investigator & \multicolumn{2}{c|}{ Participants } \\
\hline Focus groups (qualitative) & $\begin{array}{l}\text { O'Brien et al., } \\
2017^{21}\end{array}$ & $\begin{array}{l}77 \text { women living with HIV } \\
\text { (British Columbia, Ontario, } \\
\text { Quebec) }\end{array}$ & $\begin{array}{l}\text { Momen's perspectives and experiences of care in } \\
\text { Canada summarized in an envisioned model of } \\
\text { women-centred HIV care }\end{array}$ \\
\hline $\begin{array}{l}\text { Cohort surveys } \\
\text { (quantitative) }\end{array}$ & $\begin{array}{l}\text { O'Brien et al., } \\
2019^{9}\end{array}$ & $\begin{array}{l}\text { 1164 women living with HIV } \\
\text { (British Columbia, Ontario, } \\
\text { Quebec) }\end{array}$ & $\begin{array}{l}\text { Comprehensive care gaps experienced, HIV-related } \\
\text { outcomes (e.g., adherence, viral load) and women's } \\
\text { health (e.g., reproductive discussion, Papanicolaou test) }\end{array}$ \\
$\begin{array}{l}\text { Systematic review (mixed } \\
\text { methods) }\end{array}$ & $\begin{array}{l}\text { O'Brien et al., } \\
2018^{42}\end{array}$ & $\begin{array}{l}44 \text { peer-reviewed articles, } n= \\
17659 \text { women living with HIV }\end{array}$ & $\begin{array}{l}\text { Features of care at the provider, clinic and social } \\
\text { structural level found to improve access to care for } \\
\text { women living with HIV }\end{array}$ \\
\hline
\end{tabular}

The workshop was moderated professionally by an independent consultant, a francophone woman with expertise in deliberative dialogue. Rules of engagement were established, including the importance of confidentiality (Chatham House Rule) and of ensuring that different perspectives be heard. ${ }^{33,34}$ At the beginning of the deliberation, we reminded participants that they could end their participation at any time, without explanation or consequence to their care, or change in their honorarium. We also asked all workshop participants, moderators and researchers to sign a confidentiality agreement that included both the content of the discussions and the identity of fellow participants to avoid any inadvertent disclosures regarding HIV status.

The deliberation was conducted in 2 phases, 1 focused on care priorities and the other on care improvements. Both phases had 2 steps: separate small-group discussions (2 groups of 4 patients and 2 groups of 4 providers), followed by a plenary discussion with all participants.

The small, separate groups were designed to facilitate patients' comfort and engagement, in response to feedback from women living with HIV. Guiding questions designed by the investigators and professional facilitator were provided for the 2 phases (Box 2). Small-group discussions included moments of individual reflection, group discussion and group prioritization. Both small groups elected a rapporteur. As the small groups were composed of only 4 participants, facilitators were not assigned. A researcher or moderator was present to answer any clarifying questions and keep time.

Rapporteurs relayed a summary of their group's discussions to the plenary sessions for further deliberation. In the final 10 minutes of the deliberation, participants further syn- thesized their care improvements by voting on their top 3 rapid and top 3 longer-term care improvements using stickers on flip-chart paper posted around the room. As our goal was not to establish consensus, all recommendations, irrespective of rank, are reported here.

Small- and large-group deliberations were audiorecorded for subsequent transcription and analysis.

\section{Patient engagement}

In line with our participatory approach, women living with HIV who were members of the CHIWOS research team were involved in each stage of the deliberation research process, from design to dissemination.

\section{Data analysis}

The recordings were transcribed verbatim and translated from French to English by a member of the team who is fluently bilingual (N.O.). Illustrative quotes identified from the recordings were validated for accuracy by investigators present during the deliberation (L.S., K.P.B., A.D.P.). We used a thematic analysis approach ${ }^{43}$ since it allowed us to "report the experiences, meanings and reality of participants" rather than reinterpret participants' contributions. ${ }^{30,44}$ The themes thus convey the priorities and care improvements put forth by the deliberants rather than a reinterpretation conducted by the researchers at the analysis stage.

\section{Ethics approval}

This study was reviewed and approved by the Research Ethics Board of the McGill University Health Centre Research Institute.

\begin{tabular}{|l|l|}
\hline Box 2: Guiding questions for the small-group and plenary discussions* \\
\hline $\begin{array}{l}\text { Phase 1: Care } \\
\text { priorities }\end{array}$ & $\begin{array}{l}\text { - What is your response to the research presented? Is there information that } \\
\text { resonates with your knowledge or experience? }\end{array}$ \\
\hline $\begin{array}{l}\text { Phase 2: Care } \\
\text { improvements }\end{array}$ & $\begin{array}{l}\text { - If you could bring } 2-3 \text { modifications to the health care system that would } \\
\text { bring about rapid change, what would they be? (no set time specified) } \\
\text { - If you could bring 2-3 modifications to the health care system that might } \\
\text { take more time but would have a lasting impact, what would they be? (no } \\
\text { set time specified) }\end{array}$ \\
\hline *Translated from French. \\
\hline
\end{tabular}




\section{Results}

Eight patients and 8 care providers, all French speaking, participated in the deliberative dialogue. The patients, cisgendered women living with HIV, were between 40 and 60 years of age and identified as African/Caribbean/black $(n=4)$ or white $(n=4)$. Women were currently accessing HIV care from 6 different care sites and had been receiving care from the same HIV care provider for an average of 13 years (interquartile range [IQR] 5-19 yr). Care providers identified as white $(n=8)$ and as men $(n=2)$ or women $(n=6)$. They had trained as medical specialists $(n=2)$, family physicians $(n=2)$, nurses $(n=2)$ or pharmacists $(n=2)$, and provided HIV care mainly within university hospitals $(n=6)$, and private clinics $(n=2)$. Care providers had been providing care for women living with HIV for an average of 12.5 (IQR 5-18) years.

\section{Phase 1: care priorities}

Participants identified several care priorities in the small- and large-group deliberations based on the evidence presented and their experiences of care (Table 1). Patient and provider groups both highlighted the importance of integrating HIV care with other care needs as a means to address gaps in comprehensive care. Participants also prioritized the need to address HIV knowledge gaps and HIV-related stigma within health care settings to reduce needless referrals to HIV specialists for depression or routine vaccination.

Another priority identified was the need to provide public coverage for costs related to ART and for care services not currently included within the Régie de l'assurance maladie du Québec (Quebec's provincial health insurance plan), such as for psychologists or physiotherapists. Participants expressed that the lack of complete financial ART coverage (unlike in British Columbia and France) was a fundamental issue that jeopardized women's ability to access their medication and to achieve the individual and societal benefits of a suppressed viral load. Patients and providers highlighted that poverty is a common experience in this population, resulting in patients' forgoing ART in order to pay for food for their families or formula for their infants.

\section{Phase 2: care improvements}

Participants identified 4 top rapid care improvements and 3 top longer-term improvements in the small- and largegroup deliberations, distinguishing between modifications or interventions that could be implemented relatively quickly and those requiring more time and wider involvement of stakeholders (e.g., Ministry of Health) (Table 2). All topranked care improvements were identified separately in the patient and provider group discussions and were further defined and voted on in the full plenary discussion.

The top-ranked rapid improvement (10 votes) was the delegation of medical acts, as appropriate, from physicians to members of multidisciplinary care teams, such as nurses or nurse practitioners, to enable the routine provision of Papanicolaou tests and reproductive and contraceptive counselling. Certain HIV clinics in Montréal have begun delegating the provision of Papanicolaou tests, but participants believed that further efforts are required to expand this practice and make it routine.

Two care improvements tied for second, with 8 votes: greater involvement of HIV community members within health care settings and health care decision-making, and creation of a women's health information booklet. Patients advocated for women living with HIV to sit on decisionmaking committees, whereas clinicians put forth that community organizations should have a standing presence within HIV clinics to provide on-site patient support. The proposed women's health information booklet would be modelled after existing vaccination or diabetes booklets. Patients and providers stated that this would help women self-advocate for their required screenings, keep track of their appointments and enhance self-management, in line with chronic disease care models.

The third-ranked rapid care improvement (7 votes) involved educational and training strategies to improve care providers' knowledge, starting with improving the basic HIV knowledge of all care providers in the health care system, followed by raising awareness of women's care needs beyond HIV-specific care (e.g., ART, viral load) among HIV care providers.

The 3 longer-term care improvements addressed the priorities identified in the first phase of the deliberation. The top-rated longer-term improvement (11 votes) was to support ongoing initiatives that advocate for the financial coverage of ART. Participants highlighted the appropriateness of this response given the societal benefits of an undetectable viral load and the parallels between ART and other medications available at no cost to patients for the treatment of other infectious diseases. The second-ranked strategy (10 votes) was to facilitate access to health care providers not fully covered by the Régie de l'assurance maladie du Québec, especially for conditions resulting directly from HIV infection or from ART adverse effects. The third-ranked strategy ( 8 votes) was a population-wide campaign led by public health departments to increase awareness of the Undetectable $=$ Untransmittable $(\mathrm{U}=\mathrm{U})$ initiative $^{45}$ and other HIV advances. This would increase citizens' and clinicians' knowledge, which may help reduce discrimination and enable better care within the broader health care system.

\section{Interpretation}

The deliberative dialogue workshop garnered priorities and recommendations from patients and providers to improve the comprehensive care of women living with HIV in Quebec. The 4 rapid care improvements and 3 longer-term improvements identified offer stakeholder insights regarding patientcentred modifications to health care services, ranging from direct patient care to policy initiatives.

There is limited published literature on codesigned HIVspecific care recommendations. However, our findings are consistent with the HIV literature that emphasizes the need to address HIV-related stigma, ${ }^{44,46}$ promote peer-navigation 
Table 1: Priority areas identified by patients and providers, and representative quotes

Priority Illustrative quote ${ }^{*} \dagger$

Common priorities: patients and providers

Integrating HIV care with I would lump all that [HIV care] together with comprehensive care for women. Because that would address comprehensive health care almost everything. Sure, we see a specialist for HIV, but there isn't just that in the lives of women living with needs HIV. If we go to a medical clinic, even one specialized in HIV, then, well, "viral load is undetectable, CD4 is 1000 , all is good, goodbye!" Then we are promoting the idea that this is women's sole identity. ... I think care must [be comprehensive] — and l'm daring to say "must" because it's imperative that care be in line with the evolution of the HIV epidemic. Because we are often told that things have advanced, but could we also advance in the care? It's really to consider a woman as a whole person. There isn't just HIV in her life $\ldots$ it is not her identity, she is a woman. (Patient)

The integration of HIV care with other health care needs is related to this idea of comprehensive women's care. HIV is but one of the health concerns that she may have, but there can also be menopause, diabetes, being pregnant, needing contraceptive care, depression - and that all needs to be coordinated and integrated in her care. (Provider)

Increasing HIV-related knowledge of all care providers to prevent HIV-related stigma

Covering the full costs of antiretroviral therapy and care services (not currently covered by the Régie de l'assurance maladie du Québec)

Patient priorities

Diffusing the $\mathrm{U}=\mathrm{U}$ message

Addressing aging and menopause

Fostering continuity of care (same providers and across interdisciplinary providers)

\section{Provider priorities}

Situating health among women's other life priorities

How do we train providers so that there is less discrimination, so women don't end up with a gynecologist who doesn't know what a CD4 count is - and I mean training as much for social workers as doctors, as pharmacists. (Provider)

I needed to have vaccines, so I went to the [community clinic] near my house. I told the truth ... maybe the doctors needed to know what medication I was on. And they were all ready to give me the vaccine, but when I told them that [I was HIV-positive], they wrapped everything up, put everything away and said "Oh, no, we can't do that. Go see your doctor at the HIV clinic and he will give you your vaccines." (Patient) Especially with age, there are certain situations that we did not see 10 years ago — for example, joint pains, back pains - so we talk to the doctor and he refers you to a physiotherapist, etc., but often those are professionals that you have to pay out of pocket for. If you don't have private health insurance, then you get stuck paying for it, or stuck with the pain. (Patient)

I have seen many women living with HIV who are working minimum wage, 2 young children, single mom, the kids don't have anything to eat, and so she prefers to say "I will not take my ART, I can't pay for it, I will feed my kids." ... Poverty among women living with HIV is glaring. It's a top priority. What can we do? (Patient)

Here in Quebec we still pay for medication, and it's very expensive. We still have systems of copayment. Poverty is the biggest reason why patients need support programs. (Provider)

People who don't read these articles, who don't go to conferences ... they are not well-informed. We have to find other ways, like Undetectable = Untransmittable, people have to know this, because people have stayed with this old idea that HIV means death. (Patient)

Do follow-up care for women who are in menopause, because they find themselves abandoned, because they are no longer of reproductive age. (Patient, previously followed by gynecologist for contraceptives)

I also really like what we call continuity of care. I've been with the same doctor for 15 years. We talk about everything and he knows me, he doesn't even need to ask questions because, when there is a change, he knows, he sees it, and I find this very important. (Patient)

I think there should be communication between your HIV doctor and your family doctor, too. They should make a team. (Patient)

For women who we have difficulty retaining in care ... you know she had the choice between going for a job interview and going to the clinic. Or she has to go get her children at school at $3 \mathrm{pm}$, because daycare service is too expensive, and then her doctor is not available outside those times. In these circumstances, you tell yourself, it's not easy. What a battle just to get her care. (Provider)

Initiating reproductive discussions The biggest gap for women less than 50 years old is the reproductive health discussion. In each of our offices, we have a list of all screening to be done by age group, for example, Pap [smear] and mammograms are always there, but reproductive health discussion is not. I find that interesting, and it's really important for HIV now. (Provider)

Adapting to the population of people living with HIV

Delegating care acts within multidisciplinary team

Providing patient education It has historically been more of a male population, so that means that the specific care for women is really, really forgotten. (Provider)

The idea is to open up these medical acts, not just doctors but to the whole ... interdisciplinary team. The delegation of these medical acts is not very well established. (Provider)

[Patient education] is in line with HIV as a chronic disease. Chronic disease models are always models focused on the patient, focused on self-care, and so that is a part of that: awareness, education. (Provider)

Note: ART = antiretroviral therapy.

*Translated from French.

†No participant identifiers are provided given the small sample. 
Table 2 (part 1 of 2): Codesigned care improvements recommended by patients and providers, and representative quotes

\begin{tabular}{lll}
\hline Care improvement & $\begin{array}{l}\text { No. of } \\
\text { votes }\end{array}$ & Illustrative quote*
\end{tabular}

Top 4 recommendations

Delegate care to nurses and nurse practitioners

10 In our group, we were talking about interdisciplinary teams. It's up to each clinic to decide how to delegate different medical acts, certain preventive activities, women's health. (Provider)

Delegate certain professional acts, for example, to nurse practitioners: as much for you [doctors] as for us [patients]! It could be a solution that is relatively quick. (Patient)

Make space for community within HIV clinics and at different levels of decision-making

Creation of a women's health information booklet
8 Open the doors so women living with HIV could sit on decision-making committees, at the Ministry of Health, at the governmental level ... it's possible. (Patient)

Get the community within the clinic. ... For sure, this is delicate, but I know that when we add a new service to a team, at first everyone is quite uncertain, but after some time it finds its place, and those people then become essential. (Provider)

8 The second thing is a booklet or information package on comprehensive care for women, and it would have information on HIV appointments for tests (Pap [test], mammogram, etc.). And the frequencies, because sometimes we forget, or we don't know. (Patient)

So women gain responsibility, or to raise awareness among women, because it is also up to me to take charge of my health. (Patient)

There's a lot of emphasis on care guidelines for doctors and nurses. But what about a little care passport for women that they have themselves? Like a vaccination booklet. Women could say "Listen, I'm due for my Pap test." (Provider)

Training and education for all care providers

There should be awareness-building and knowledge-transfer workshops for care providers, nurses, doctors, etc., who are not in the HIV sector. ... Because if they know how it gets transmitted, then they will be less afraid. (Patient)

There's [a provincial initiative] trying to implement provincial training so that a person in [rural Quebec] can go online and get the training on "HIV 101." Outside of Montréal, there are so few [people living with HIV], so it's not so much a lack of interest as misconceptions, and then it's scary: "I don't really want to get too close because I don't understand." So what we are doing is having a designated person in each family medicine unit who is [trained] in substance use, hepatitis and HIV, to increase the confidence levels with these disorders. (Provider)

We have to remind ourselves that, for many women, their HIV doctor is the only doctor they see ... the HIV care providers should also be women's providers for their comprehensive care needs. (Provider)

Other recommendations

CHIWOS researcher should present research results
2 The CHIWOS researchers should present results to each multidisciplinary team so that they can then make concrete tools to improve their care practice.... Just having this discussion this afternoon wakes us up to what we could all do in our clinics, but I think it could be broadened by going to each clinic. (Provider)

2 Like a list of resources ... for providers to be able to orient patients adequately within the health care system and avoid instances where they feel discriminated against, while we wait for education to be done. (Provider)
Creation of resources

booklet to facilitate communication among providers

\section{Longer-term}

Top 3 recommendations

Full financial coverage of antiretroviral therapy in context of $\mathrm{U}=\mathrm{U}$

Health service coverage

$\mathrm{U}=\mathrm{U}$ public campaign
I agree that it would take a lot of political will and a lot of work, but the moment it is implemented, it will change the entire landscape. (Provider)

Full coverage of other health services and, most importantly, ART. (Patient)

10 Free access to mental health services for people living with HIV. (Provider).

People should have access to care like physiotherapy or kinesiology or something like that, if [the problem is] following side effects of the medication or is due to HIV itself. (Patient)

8 We would really appreciate if public health - so, starting from the top instead of from the ground up - if they'd continue to inform the population on HIV, but to do so around $U=U$, and that it be widely diffused to the whole population, so that the message is received more effectively. (Patient)

There are challenges regarding HIV knowledge, the lack of overall HIV knowledge of care providers in the health care system. And it's true that, at the ministry level, there is not a lot of efforts being made for $\mathrm{U}=\mathrm{U}$. Sure, it's new, but still, there is a lack of knowledge. Even just that $\mathrm{HIV}$ is a chronic disease now. We need to be doing whole-person care. (Provider) 
Table 2 (part 2 of 2): Codesigned care improvements recommended by patients and providers, and representative quotes

\begin{tabular}{|c|c|c|}
\hline Care improvement & $\begin{array}{l}\text { No. of } \\
\text { votes }\end{array}$ & Illustrative quote ${ }^{*} \dagger$ \\
\hline \multicolumn{3}{|l|}{ Other recommendations } \\
\hline $\begin{array}{l}\text { Facilitate family doctors as } \\
\text { care providers }\end{array}$ & 3 & $\begin{array}{l}\text { I'm a huge advocate for family doctors to continue to do routine HIV follow-up, because it brings } \\
\text { a comprehensive care approach, and it's a specificity that we have here in Quebec that isn't } \\
\text { everywhere. ... HIV clinics, in my opinion, should really have an approach that is much more a } \\
\text { chronic disease approach, like diabetes, like hypertension. (Provider) }\end{array}$ \\
\hline \multirow[t]{2}{*}{ Outreach nursing care } & 2 & $\begin{array}{l}\text { This might not be required for everyone, but outreach nursing care or follow-up care by phone } \\
\text { [should be available]. For people to not always have to be the ones travelling, sometimes there } \\
\text { are things that can be done by phone, or some blood draws that don't need an appointment. } \\
\text { (Provider) }\end{array}$ \\
\hline & & $\begin{array}{l}\text { [Outreach nursing care] is already offered for active drug users, but for the woman who is a } \\
\text { single mom, working - well, her, she needs to come in for an appointment. (Provider) }\end{array}$ \\
\hline $\begin{array}{l}\text { Mandatory health days } \\
\text { within labour codes }\end{array}$ & 1 & $\begin{array}{l}\text { Employees are quite hesitant to ask for time off on a pretty regular basis. They don't want to } \\
\text { make their employer think that they have something. (Provider) }\end{array}$ \\
\hline
\end{tabular}

programming, ${ }^{47,48}$ integrate women's health in HIV care ${ }^{14,21}$ and increase supports for self-management ${ }^{49}$ in a chronic disease era. The deliberative outputs also provide compelling endorsement of care improvement efforts already underway in Quebec. These include campaigns to fully cover ART costs, ${ }^{50,51}$ awareness campaigns for $\mathrm{U}=\mathrm{U}, 45,52$ education for providers ${ }^{53}$ and the delegation of care acts within multidisciplinary teams. ${ }^{54}$

Further research where the object of the research is the partnership or process of patient engagement itself is needed to investigate whether codesign strategies are truly meeting their aims and whether patient engagement efforts include a diversity of voices. ${ }^{37,55}$ Investigating the implementation and impact of deliberative approaches is also required to understand the extent to which deliberative outputs are used to enact change and to identify what additional efforts may be required to transform recommendations into actual care improvements.

\section{Limitations}

The deliberation was conducted in Montréal. Priorities and recommendations may vary in other provinces with different health policies and practices, or in rural settings with more limited resources. Although a range of patients and providers participated, younger women ( $<40 \mathrm{yr}$ of age) were not represented and may have provided differing patient perspectives. The absence of policy-makers or stakeholders mandated to enact the recommendations is also a limitation.

\section{Lessons learned from patient and care provider engagement}

As Abelson and colleagues ${ }^{40}$ acknowledge, the centrality of power differentials cannot be excluded from the public sphere of deliberative dialogue, although certain strategies may be adopted to enable productive conversations and the codesign of care recommendations to occur. In our deliberation, where power gradients were particularly steep between care providers and patients, we adopted 3 strategies that appeared to be suc- cessful in facilitating engagement: setting rules of engagement; planning separate and mixed patient and provider deliberations; and recruiting patients with previous experience in AIDS service organizations and participatory research projects.

Patients with previous participatory research experience provided an essential communication bridge during the workshop, relaying information between small patient groups and large mixed-group deliberations. Although there is reticence in the patient engagement literature regarding the role of "professional patients" or "super patients," ${ }^{15-57}$ our experience suggests that this expertise may be essential for ensuring that the full range of patient perspectives are heard. Since patients with HIV and affected communities have been a central part of the HIV response since the onset of the epidemic, providers also had previous experience engaging with patients beyond individual clinical care. This familiarity with community-academic partnerships in the field of HIV undoubtedly facilitated productive discussions and enabled the codesign of care recommendations.

Although we did not evaluate the process of our deliberation explicitly, our results show the first intended effect of a deliberation, which is to promote mutual agreement on an issue. ${ }^{33}$ For instance, a $\mathrm{U}=\mathrm{U}$ public information campaign was brought forward as a priority area by 1 patient group in the first phase of the deliberation and was then recommended as a care improvement by all 4 small groups in the second phase. This suggests that agreement on priorities and recommendations can occur across stakeholder groups within a single workshop and that patients can shape the final care recommendations put forth.

\section{Conclusion}

Our deliberative dialogue workshop was found to be a productive mechanism for the creation of stakeholder recommendations informed by research evidence and the lived experience of patients and providers. These recommendations can be used 
to inform policy and care initiatives in Quebec, as well as care modifications in other jurisdictions. The stakeholder recommendations provide strategies that range from populationwide $\mathrm{HIV}$-awareness campaigns to patient-focused diseasemanagement tools. Together, these strategies can inform health care modifications to address gaps in comprehensive care experienced by women living with HIV in Canada.

\section{References}

1. Chu C, Selwyn PA. An epidemic in evolution: the need for new models of HIV care in the chronic disease era. 7 Urban Health 2011;88:556-66.

2. Justice AC. HIV and aging: time for a new paradigm. Curr HIVIAIDS Rep 2010; 7:69-76.

3. Kendall CE, Shoemaker ES, Boucher L, et al. The organizational attributes of HIV care delivery models in Canada: a cross-sectional study. PLoS One 2018; 13:e0199395.

4. Deeks SG, Lewin SR, Havlir DV. The end of AIDS: HIV infection as a chronic disease. Lancet 2013;382:1525-33.

5. Patterson S, Cescon A, Samji H, et al. Life expectancy of HIV-positive individuals on combination antiretroviral therapy in Canada. BMC Infect Dis 2015;15:274.

6. HIV/AIDS Epi updates, July 2010. Ottawa: Public Health Agency of Canada; 2010. Available: https://www.canada.ca/en/public-health/services/hiv-aids/ publications/epi-updates.html (accessed 2019 Aug. 18).

7. HIV/AIDS status report: women. Ottawa: Public Health Agency of Canada; 2012. Available: https://www.canada.ca/en/public-health/services/hiv-aids/ publications/population-specific-hiv-aids-status-reports/women.html (accessed 2019 July 27).

8. Haddad N, Li JS, Totten S, et al. HIV in Canada - surveillance report, 2017. Can Commun Dis Rep 2018;44:348-56.

9. O'Brien N, Godard-Sebillotte C, Skerritt L, et al. Assessing gaps in comprehensive HIV and women's health care across a typology of care for women living with HIV in Canada. 10th IAS Conference on HIV Science; 2019 Sept. 21-24; Mexico City.

10. Gokhale RH, Bradley H, Weiser J. Reproductive health counseling delivered to women living with HIV in the United States. AIDS Care 2017;29:928-35.

11. Finocchario-Kessler S, Mabachi N, Dariotis JK, et al. 'We weren't using condoms because we were trying to conceive': the need for reproductive counseling for HIV-positive women in clinical care. AIDS Patient Care STDS 2012;26:700-7.

12. Loutfy M, Kennedy VL, Poliquin V, et al. No. 354 - Canadian HIV pregnancy planning guidelines. 7 Obstet Gynaecol Can 2018;40:94-114.

13. Zash R, Makhema J, Shapiro R. Neural-tube defects with dolutegravir treatment from the time of conception. N Engl 7 Med 2018;379:979-81.

14. Salters K, Loutfy M, de Pokomandy A, et al. Pregnancy incidence and intention after HIV diagnosis among women living with HIV in Canada. PLoS One 2017;12:e0180524.

15. Gardner EM, McLees MP, Steiner JF, et al. The spectrum of engagement in $\mathrm{HIV}$ care and its relevance to Test-and-Treat strategies for prevention of HIV infection. Clin Infect Dis 2011;52:793-800.

16. Kerkerian G, Kestler M, Carter A, et al. Attrition across the HIV cascade of care among a diverse cohort of women living with HIV in Canada. 7 Acquir Immune Defic Syndr 2018;79:226-36.

17. Kronfli N, Lacombe-Duncan A, Wang Y, et al. Access and engagement in HIV care among a national cohort of women living with HIV in Canada. AIDS Care 2017;29:1235-42.

18. Girardi E, Sabin CA, d'Arminio Monforte A. Late diagnosis of HIV infection: epidemiological features, consequences and strategies to encourage earlier testing. 7 Acquir Immune Defic Syndr 2007;46:S3-8.

19. Puskas CM, Forrest JI, Parashar S, et al. Women and vulnerability to HAART non-adherence: a literature review of treatment adherence by gender from 2000 to 2011. Curr HIV/AIDS Rep 2011;8:277-87.

20. Nicastri E, Leone S, Angeletti C, et al. Sex issues in HIV-1-infected persons during highly active antiretroviral therapy: a systematic review. 7 Antimicrob Chemother 2007;60:724-32.

21. O'Brien N, Greene S, Carter A, et al. Envisioning women-centered HIV care: perspectives from women living with HIV in Canada. Womens Health Issues 2017;27:721-30.

22. Robert G, Cornwell J, Locock L, et al. Patients and staff as codesigners of healthcare services. BM7 2015;350:g7714.

23. Experience-based co-design toolkit. London (UK): The King's Fund. Available: www.kingsfund.org.uk/projects/point-care/ebcd (accessed 2019 Aug. 18).

24. Miller FA, Patton SJ, Dobrow M, et al. Public involvement in health research systems: a governance framework. Health Res Policy Syst 2018;16:79.

25. Palmer VJ, Weavell W, Callander R, et al. The Participatory Zeitgeist: an explanatory theoretical model of change in an era of coproduction and codesign in healthcare improvement. Med Humanit 2019;45:247-57.

26. Martin D, Miller AP, Quesnel-Vallée A, et al. Canada's universal health-care system: achieving its potential. Lancet 2018;391:1718-35.
27. Loutfy M, de Pokomandy A, Kennedy VL, et al. Cohort profile: the Canadian HIV Women's Sexual and Reproductive Health Cohort Study (CHIWOS). PLoS One 2017;12:e184708.

28. Minkler M, Wallerstein N, editors. Community-based participatory research for health: from process to outcomes. San Francisco: Jossey Bass (Wiley); 2011.

29. Cargo M, Mercer SL. The value and challenges of participatory research: strengthening its practice. Annu Rev Public Health 2008;29:325-50.

30. Evans R, Kotchetkova I. Qualitative research and deliberative methods: Promise or peril? Qual Res 2009;9:625-43.

31. Burchardt T. Deliberative research as a tool to make value judgements. Qual Res 2013;14:353-70.

32. Lomas J, Canadian Health Services Research Foundation, Provincial/Territorial Conference of Deputy Ministers of Health. Task Force on Wait Times. Conceptualizing and combining evidence for health system guidance: final report. Ottawa: Canadian Health Services Research Foundation; 2005. Available: https://www.cfhi-fcass.ca/migrated/pdf/insightAction/evidence_e.pdf (accessed 2019 Aug. 26).

33. Boyko JA, Lavis JN, Abelson J, et al. Deliberative dialogues as a mechanism for knowledge translation and exchange in health systems decision-making. Soc Sci Med 2012;75:1938-45.

34. Lavis JN, Boyko JA, Gauvin FP. Evaluating deliberative dialogues focused on healthy public policy. BMC Public Health 2014;14:1287.

35. Collins HM, Evans R. The third wave of science studies: studies of expertise and experience. Soc Stud Sci 2002;32:235-96.

36. Buchanan A, O'Neill M. Inclusion and diversity: finding common ground for organizational action: a deliberative dialogue guide. Ottawa: Canadian Council for International Co-operation; 2001. Available: https://www.racialequitytools. org/resourcefiles/buchanan2.pdf (accessed 2020 Apr. 2).

37. Greenhalgh T, Jackson C, Shaw S, et al. Achieving research impact through co-creation in community-based health services: literature review and case study. Milbank Q 2016;94:392-429.

38. IAP2's Public Participation Spectrum. International Association for Public Participation (IAP2); 2014. Available: https://cdn.ymaws.com/www.iap2.org/resource/ resmgr/foundations_course/IAP2_P2_Spectrum_FINAL.pdf (accessed 2019 Aug. 26).

39. Longo C, Rahimzadeh V, O'Doherty $\mathrm{K}$, et al. Addressing ethical challenges at the intersection of pharmacogenomics and primary care using deliberative consultations. Pharmacogenomics 2016;17:1795-805.

40. Abelson J, Forest PG, Eyles J, et al. Deliberations about deliberative methods: issues in the design and evaluation of public participation processes. Soc Sci Med 2003;57:239-51

41. Abelson J, Tripp L, Sussman J. 'I just want to be able to make a choice': results from citizen deliberations about mammography screening in Ontario, Canada. Health Policy 2018;122:1364-71.

42. O'Brien N, Hong QN, Law S, et al. Health system features that enhance access to comprehensive primary care for women living with HIV in high-income settings: a systematic mixed studies review. AIDS Patient Care STDS 2018;32:129-48.

43. Braun V, Clarke V. Using thematic analysis in psychology. Qual Res Psychol 2006;3:77-101.

44. Engler K, Lessard D, Lebouché B. A review of HIV-specific patient-reported outcome measures. Patient 2017;10:187-202.

45. Undetectable $=$ Untransmittable. Prevention Access Campaign; 2019. Available: https://www.preventionaccess.org/about (accessed 2019 Aug. 26).

46. Andersson GZ, Reinius M, Eriksson LE, et al. Stigma reduction interventions in people living with HIV to improve health-related quality of life. Lancet HIV 2020;7:e129-40.

47. Greene S, Ion A, Kwaramba G, et al. "Trust me, it's different": experiences of peer case management of women living with HIV in Ontario, Canada. Can Soc Work Rev 2015;32:73-93.

48. Broeckaert L. Practice guidelines in peer health navigation for people living with HIV. Toronto: Canadian AIDS Treatment Information Exchange; 2018. Available: https://www.catie.ca/en/peernavigation-guidelines (accessed 2020 Mar. 4).

49. Boucher LM, O'Brien KK, Baxter LN, et al. Healthy aging with HIV: the role of self-management support. Patient Educ Couns 2019;102:1565-9.

50. The Access + portrait: barriers and facilitators in accessing care and treatment for people living with HIV in Quebec. Montréal: Programme national de mentorat sur le VIH et les hépatites; 2019. Available: https://pvsq.org/sites/default/ files/resume_portrait_acces_.pdf (accessed 2019 Aug. 26).

51. Treatments. Montréal: Coalition of Quebec Community Organizations Fighting AIDS; 2010. Available: https://cocqsida.com/nos-dossiers/traitements.html (accessed 2019 Aug. 26).

52. Communication to fight stigma and discrimination. Montréal: Montréal Without AIDS; 2019. Available: www.montrealsanssida.ca/axe1/ (accessed 2019 Aug. 26).

53. Documentation Centre. Montréal: Programme national de mentorat sur le VIH et les hépatites; 2019. Available: https://pnmvh.org/centre-de -documentation/?theme\&document-categorie=trousse-de-depart (accessed 2019 Aug. 26)

54. Kestler M, Murray M, Money D, et al. The Oak Tree Clinic: the envisioned model of care for women living with human immunodeficiency virus in Canada. Womens Health Issues 2018;28:197-8. 
55. Shimmin C, Wittmeier KDM, Lavoie JG, et al. Moving towards a more inclusive patient and public involvement in health research paradigm: the incorporation of a trauma-informed intersectional analysis. BMC Health Serv Res 2017; $17: 539$.

56. Holmes BJ, Bryan S, Ho K, et al. Engaging patients as partners in health research: lessons from BC, Canada. Healthc Manage Forum 2018;31:41-4.

57. Black A, Strain K, Wallsworth C, et al. What constitutes meaningful engagement for patients and families as partners on research teams? 7 Health Serv Res Policy 2018;23:158-67.

Affiliations: Departments of Family Medicine (O'Brien, Skerritt, Andersson, de Pokomandy) and Epidemiology, Biostatistics and Occupational Health (Cox), McGill University; Chronic Viral Illness Service (O’Brien, Proulx-Boucher, Ménard, Cox, de Pokomandy), Department of Medicine, McGill University Health Centre, Montréal, Que.; Institute for Better Health (Law), Trillium Health Partners, Mississauga, Ont.; Institute for Health Policy, Management \& Evaluation (Law), University of Toronto, Toronto, Ont.; Department of Obstetrics and Gynecology (Boucoiran), Centre hospitalier universitaire Sainte-Justine; Departments of Social and Preventive Medicine (Boucoiran) and Obstetrics and Gynecology (Boucoiran), Université de Montréal, Montréal Que.; Centro de Investigación de Enfermedades Tropicales (Andersson), Universidad Autónoma de Guerrero, Acapulco, Mexico.
Contributors: Susan Law, Joseph Cox, Neil Andersson and Alexandra de Pokomandy supervised the project. Nadia O'Brien, Susan Law, Brigitte Ménard, Isabelle Boucoiran, Joseph Cox, Neil Andersson and Alexandra de Pokomandy conceived the study. Nadia O'Brien designed the study with methodologic input from Susan Law and Neil Andersson. Karène Proulx-Boucher and Lashanda Skerritt assisted in data collection during the deliberative workshop. Nadia O'Brien analyzed and interpreted the data and drafted the manuscript. All of the authors revised the manuscript critically for important intellectual content, approved the final version to be published and agreed to be accountable for all aspects of the work.

Data sharing: Anonymized portions of the transcripts in which it is not possible to identify the participant may be made available to other researchers by contacting the corresponding author.

Acknowledgement: The authors thank Miriam Fahmy for lending her deliberative workshop expertise to this project. Her skilled and sensitive moderation was tremendously appreciated.

Supplemental information: For reviewer comments and the original submission of this manuscript, please see www.cmajopen.ca/content/8/2/ E264/suppl/DC1. 